\title{
Molecular and immunohistochemical effects of metformin in a rat model of type 2 diabetes mellitus
}

\author{
TAMER AHMED ISMAIL ${ }^{1,2}$, MOHAMED MOHAMED SOLIMAN ${ }^{1,3}$ and MOHAMED ABDO NASSAN ${ }^{4}$
}

\author{
${ }^{1}$ Medical Laboratory Department, Faculty of Applied Medical Sciences, Taif University, Taif, Mecca 21995, \\ Saudi Arabia; ${ }^{2}$ Department of Physiology, Faculty of Veterinary Medicine, Zagazig University, Zagazig, Sharqia 44519; \\ ${ }^{3}$ Department of Biochemistry, Faculty of Veterinary Medicine, Benha University, Benha, Al Qalyubia 13736; \\ ${ }^{4}$ Department of Pathology, Faculty of Veterinary Medicine, Zagazig University, Zagazig, Sharqia 44519, Egypt
}

Received August 30, 2014; Accepted March 5, 2015

DOI: $10.3892 / \mathrm{etm} .2015 .2354$

\begin{abstract}
Type 2 diabetes mellitus (T2DM) is a serious health issue worldwide. The disease is characterized by insulin resistance (IR), which leads to dyslipidemia and alterations in the expression levels of a number of genes. Metformin is the standard treatment for T2DM; however, the exact mechanism underlying metformin regulation is not fully understood. The aim of the present study was to investigate the effects of metformin on serum lipid profiles and the expression levels of various genes that are associated with IR, as well as the histopathological changes in the liver and pancreas. A T2DM rat model was established by feeding the rats a high-fat diet for 4 weeks, combined with a dose of streptozotocin $(35 \mathrm{mg} / \mathrm{kg}$ body weight). Following the successful induction of T2DM, metformin was administered orally (400 mg/kg/day) for
\end{abstract}

Correspondence to: Professor Mohamed Mohamed Soliman, Department of Biochemistry, Faculty of Veterinary Medicine, Benha University, El-Shaheed Farid Nada, Benha, Al Qalyubia 13736, Egypt

E-mail: mohamedsoliman8896@yahoo.com

Abbreviations: ACO, acyl-CoA oxidase; ACS, acyl-CoA synthetase; AMPK, adenosine monophosphate-activated protein kinase; MAPK, mitogen-activated protein kinase; apo C-III, apolipoprotein C-III; CNS, central nervous system; CPT-1, carnitine palmitoyl transferase-1; FAS, fatty acid synthetase; GLUT-4, glucose transporter-4; HDL, high-density lipoprotein; HFD, high-fat diet; HFFD, high-fat fructose diet; IR, insulin resistance; IRS, insulin receptor substrates; LDL, low-density lipoprotein; LPL, lipoprotein lipase; PI3K, phosphatidyl inositol 3 kinase; PKB, protein kinase B; PPAR- $\alpha$, peroxisome proliferator activated receptor- $\alpha$; PBS, phosphate-buffered saline; RT-PCR, reverse transcription-polymerase chain reaction; RBP-4, retinol binding protein-4; STZ, streptozotocin; T2DM, type 2 diabetes mellitus; TC, total cholesterol; TG, triglycerides; VLDL, very low-density lipoprotein; ACC, acyl-CoA cyclase; TNF, tumor necrosis factor

Key words: type 2 diabetes, metformin, immunohistochemistry, fetuin-A, perilipin, mRNA expression
4 weeks. The results indicated that metformin improved the symptoms of IR by normalizing the serum lipid profiles in the diabetic rats. Furthermore, metformin upregulated the expression of insulin receptors and genes associated with lipid metabolism, including acyl-CoA oxidase, carnitine palmitoyl transferase- 1 and peroxisome proliferator activated receptor- $\alpha$. In addition, treatment with metformin downregulated the expression levels of fetuin-A and retinol binding protein-4 (RBP-4), while normalizing the expression of perilipin that had been reduced in the T2DM rats. Metformin administration induced regenerative changes in the hepatocyte cytoplasm and parenchyma. In the pancreas, treatment with metformin was shown to induce positive signaling for insulin and the regeneration of pancreatic $\beta$ cells. In summary, metformin treatment ameliorated a number of the harmful effects associated with T2DM via the modulation of the expression levels of fetuin-A, RBP-4, perilipin and various genes associated with lipid metabolism, resulting in regenerative changes in the liver and pancreatic cells.

\section{Introduction}

In 2010, 285 million individuals were estimated to have been diagnosed with diabetes mellitus worldwide, a prevalence of $6.4 \%$, which is predicted to increase to 439 million (7.7\%) by 2030 (1). The mortality rate of diabetes mellitus, including indirect mortalities, is estimated to be $\sim 3.96$ million per year for all age groups, which is a prevalence of $6.8 \%$ (2). Type 2 diabetes mellitus (T2DM) accounts for $\sim 90 \%$ of diabetes cases worldwide (1). T2DM has been described as a 'silent disease' (3) and is characterized by a combination of inadequate insulin secretion due to islet $\beta$ cell deterioration and insulin resistance (IR) (3). Interruption of pancreatic $\beta$ cell function and insulin activity characterizes T2DM, resulting in symptoms which include dyslipidemia, hyperglycemia, hypertension and atherosclerosis, which subsequently contribute to reduced insulin sensitivity (4).

T2DM is associated with IR, which induces a range of detrimental effects in various organs and tissues. The impact of IR on the central nervous system (CNS) may lead to obesity, as the appetite may be enhanced as a result of the activity of insulin in the CNS (5). In adipose tissue, IR causes hyperlip- 
idemia. Under normal conditions, insulin promotes adipocyte differentiation and glucose uptake, while inhibiting lipolysis in adipocytes. Furthermore, adipose tissue is able to function as an endocrine organ by releasing cytokines and hormones, a function which is disrupted by fat expansion, thus promoting IR (6). In pancreatic tissue, IR impairs $\beta$ cell regeneration (7). However, whether insulin has a direct autocrine function on $\beta$ cells in promoting insulin secretion is yet to be fully elucidated (8).

Jung et al (9) identified a novel hepatokine secreted by the liver, named fetuin-A, which was found to be associated with obesity, IR and non-alcoholic fatty liver disease. Fetuin-A affects insulin signal transduction by inhibiting the activity of the insulin receptor tyrosine kinase in the liver and skeletal muscle, in addition to mitigating insulin receptor autophosphorylation in vitro and in vivo, subsequently resulting in IR (10). An additional novel biological marker that can function as a reliable indicator of IR is retinol binding protein-4 (RBP-4). RBP-4 may serve crucial functions in the development of IR and atherosclerosis in T2DM patients with coronary artery disease. Further study of these marker proteins and peptides may aid in the diagnosis and alleviation of IR (11). Perilipins are a family of proteins that target the surfaces of lipid droplets to regulate lipid storage and hydrolysis. A previous study investigating perilipin activity indicated the physiological function of cytosolic lipid droplets and their association with obesity-associated diseases, such as IR (12).

Metformin hydrochloride is one of the most commonly used treatments for T2DM. Metformin improves insulin sensitivity, reduces gluconeogenesis, promotes glucose uptake and reduces glucose production in the liver $(13,14)$. In combination with lifestyle modifications, metformin is the primary glucose-lowering agent used in the treatment of T2DM, due to its efficacy, safety and beneficial cardiovascular and metabolic activity $(15,16)$. Notably, metformin exerts pleiotropic effects in a number of tissues that are affected by IR and hyperinsulinemia, such as skeletal muscles, adipose tissue and the endothelium (17). Although metformin has been used in clinical practice for $>40$ years, the exact underlying mechanism of action is yet to be fully elucidated (18).

The present study investigated the effects of metformin on dyslipidemia and the expression of genes associated with lipid metabolism in T2DM rats. The effects of metformin were assessed at a molecular and immunohistopathological level.

\section{Materials and methods}

Reagents. Streptozotocin (STZ) and metformin were purchased from Sigma-Aldrich (St. Louis, MO, USA). Wistar albino rats were purchased from Egyptian Co. for Experimental Animals Production (Helwan, Egypt). Solvents and associated reagents were purchased from ADWIA Pharmaceuticals (Obour City, Egypt). The high-fat diet (HFD) was purchased from Qaha Co. for Food Production (Qaha, Egypt). Biochemical kits to assess the lipids profiles were obtained from Clini Lab (Heliopolis, Egypt).

Induction of T2DM and experimental design. In total, 30 male Wistar rats (age, 4 weeks; weight, 80-100 g) were selected at random. The rats were exposed to a 12-h day/night cycle, with free access to food and water. The present study was approved by the Ethics Committee on Animal Care of Taif University (Taif, Saudi Arabia; project no. \#3103/1435/1). Rats were divided into three groups ( $\mathrm{n}=10$ per group). Control group rats received a normal diet. In order to induce IR and T2DM, the remaining 20 rats received a HFD for 4 weeks, which consisted of $15.5 \%$ protein, $38.8 \%$ fat and $45.7 \%$ carbohydrates, by calories. Induction of T2DM in the HFD-fed rats was based on the protocol outlined by Srinivasan et al (19), which comprised an intraperitoneal injection of STZ (35 mg/ $\mathrm{kg}$ body weight), followed by administration of the HFD for 4 weeks. T2DM was confirmed after 1 week, as serum glucose levels and lipid profiles were increased. The T2DM rats $(n=20)$ were subsequently divided into two subgroups, namely the T2DM group $(n=10)$ and the T2DM + metformin group $(n=10)$, in which metformin (400 mg/kg/day) was administered for 4 weeks.

Following the experimental procedures, all rats were decapitated following inhalation of diethyl ether and after overnight fasting and blood samples were collected for serum extraction and serum chemistry analysis. In addition, liver and adipose tissues were maintained in TRIzol reagent (Invitrogen Life Technologies, Carlsbad, CA, USA) for RNA extraction and semi-quantitative reverse transcription-polymerase chain reaction (RT-PCR) analysis of gene expression.

Serum chemistry analysis. Levels of serum triglycerides (TG), total cholesterol (TC), low-density lipoproteins (LDLs), very low-density lipoproteins (VLDLs) and high-density lipoproteins (HDLs) were measured using commercial spectrophotometric analysis kits. Insulin and glucose levels were measured using spectrophotometric commercial kits. All the kits were purchased from Bio-Diagnostic Company (Giza, Egypt).

cDNA synthesis, semi-quantitative RT-PCR analysis and gene expression. Liver and epididymal adipose tissues were collected from rats, flash frozen in $1 \mathrm{ml}$ TRIzol reagent and subsequently stored at $-70^{\circ} \mathrm{C}$. Frozen samples $(\sim 100 \mathrm{mg}$ tissue per sample) were immediately homogenized using a POLYTRON 300 D homogenizer (Brinkmann Instruments, Inc., Westbury, NY, USA). Total RNA was extracted via chloroform extraction, which was followed by nucleic acid precipitation with isopropanol. The pellet was washed with $75 \%$ ethanol and resuspended in molecular biology grade water. The nucleic acid concentration was measured at an optical density of $260 \mathrm{~nm}$ using a SmartSpec spectrophotometer (Bio-Rad Laboratories, Inc., Hercules, CA, USA). The RNA integrity was evaluated using an Agilent 2100 Bioanalyzer (Agilent Technologies, Inc., Foster City, CA, USA).

RNA $(1 \mu \mathrm{g})$ was treated at $70^{\circ} \mathrm{C}$ for $5 \mathrm{~min}$ and reverse transcribed using 100 units Moloney Murine Leukemia Virus Reverse Transcriptase (Gibco Life Technologies, Carlsbad, CA, USA), 50 pmol poly (dT) primer and $20 \mathrm{nmol}$ dNTPs, in a total volume of $10 \mu \mathrm{l}$ at $37^{\circ} \mathrm{C}$ for $1 \mathrm{~h}$. After heating at $94^{\circ} \mathrm{C}$ for $5 \mathrm{~min}, \mathrm{PCR}$ amplification was performed using 2.5 units Taq polymerase (PerkinElmer, Inc., Waltham, MA, USA), $3 \mathrm{mM} \mathrm{MgCl}$ and 50 pmol forward and reverse primers specific for the respective genes, in a total volume of $25 \mu 1$. The PCR conditions for the various genes investigated are presented in Table I. PCR products were visualized under an 
Table I. Polymerase chain reaction conditions for the genes analyzed.

\begin{tabular}{|c|c|c|c|c|}
\hline Gene & Product size (bp) & Annealing temp $\left({ }^{\circ} \mathrm{C}\right)$ & Direction & Sequence \\
\hline Fetuin-A & 260 & 55.5 & $\begin{array}{l}\text { Sense } \\
\text { Antisense }\end{array}$ & $\begin{array}{l}\text { CCAGTGTCATTCCACCAGA } \\
\text { CGCAGCTATCACAAACTCCA }\end{array}$ \\
\hline FAS & 345 & 61 & $\begin{array}{l}\text { Sense } \\
\text { Antisense }\end{array}$ & $\begin{array}{l}\text { CCAGAGCCCAGACAGAGAAG } \\
\text { GACGCCAGTGTTCGTTCC }\end{array}$ \\
\hline IRS-1 & 337 & 53.5 & $\begin{array}{l}\text { Sense } \\
\text { Antisense }\end{array}$ & $\begin{array}{l}\text { GCCAATCTTCATCCAGTTGC } \\
\text { CATCGTGAAGAAGGCATAGG }\end{array}$ \\
\hline IRS-2 & 151 & 55 & $\begin{array}{l}\text { Sense } \\
\text { Antisense }\end{array}$ & $\begin{array}{l}\text { CTACCCACTGAGCCCAAGAG } \\
\text { CCAGGGATGAAGCAGGACTA }\end{array}$ \\
\hline $\mathrm{ACO}$ & 633 & 53 & $\begin{array}{l}\text { Sense } \\
\text { Antisense }\end{array}$ & $\begin{array}{l}\text { GCCCTCAGCTATGGTATTAC } \\
\text { AGGAACTGCTCTCACAATGC }\end{array}$ \\
\hline CPT-1 & 628 & 52 & $\begin{array}{l}\text { Sense } \\
\text { Antisense }\end{array}$ & $\begin{array}{l}\text { TATGTGAGGATGCTGCTTCC } \\
\text { CTCGGAGAGCTAAGCTTGTC }\end{array}$ \\
\hline Perilipin & 260 & 53.5 & $\begin{array}{l}\text { Sense } \\
\text { Antisense }\end{array}$ & $\begin{array}{l}\text { ACACTCTTTCTCGACACACC } \\
\text { CTGGTCTTCATGGTTCTCAT }\end{array}$ \\
\hline PPAR- $\alpha$ & 680 & 59 & $\begin{array}{l}\text { Sense } \\
\text { Antisense }\end{array}$ & $\begin{array}{l}\text { GAGGTCCGATTCTTCCACTG } \\
\text { ATCCCTGCTCTCCTGTATGG }\end{array}$ \\
\hline G3PDH & 309 & 52 & $\begin{array}{l}\text { Sense } \\
\text { Antisense }\end{array}$ & $\begin{array}{l}\text { AGATCCACAACGGATACATT } \\
\text { TCCCTCAAGATTGTCAGCAA }\end{array}$ \\
\hline
\end{tabular}

FAS, fatty acid synthetase; IRS, insulin receptor substrate; ACO, acyl-CoA oxidase; CPT-1, carnitine palmitoyl transferase-1; PPAR, peroxisome proliferator activated receptor; G3PDH, glyceraldehyde-3-phosphate dehydrogenase.

ultra-violet lamp following electrophoresis in $1.5 \%$ agarose gel stained with ethidium bromide. Intensities of the PCR bands were analyzed densitometrically using ImageJ software (version 1.48; http://imagej.en.softonic.com).

Liver and pancreatic histopathology and immunohistochemistry. Rats were anesthetized with diethyl ether and the liver was incised. Following removal of the liver from the rats, the liver was fixed overnight in $10 \%$ buffered neutral formalin solution. Fixed tissues were processed routinely by washing, dehydration, clearing, paraffin embedding, casting and sectioning into 5- $\mu \mathrm{m}$ slices for hematoxylin and eosin staining (20). With regard to immunohistochemistry, pancreatic tissue sections were deparaffinized and treated with $3 \%$ $\mathrm{H}_{2} \mathrm{O}_{2}$ for $10 \mathrm{~min}$ to inactivate the peroxidases. Subsequently, the tissue samples were heated in $10 \mathrm{mM}$ citrate buffer at $121^{\circ} \mathrm{C}$ for $30 \mathrm{~min}$ for antigen retrieval, blocked in $5 \%$ normal serum for $20 \mathrm{~min}$, and incubated with a rabbit polyclonal anti-insulin primary antibody (1:100; sc-9168; Santa Cruz Biotechnology, Inc., Dallas, TX, USA) in phosphate-buffered saline (PBS) overnight at $4^{\circ} \mathrm{C}$. After three extensive washes with PBS, the sections were incubated with a goat anti-rabbit IgG biotin-conjugated secondary antibody (1:2,000; sc-2040; Santa Cruz Biotechnology, Inc.) for $20 \mathrm{~min}$ at $32^{\circ} \mathrm{C}$. After further incubation with horseradish peroxidase-labeled streptavidin, antibody binding was visualized using diaminobenzidine, and the sections were counterstained with hematoxylin. Tissue slides were visualized using a Wolfe S9-0982 microscope (Carolina Biological Supply Co., Burlington, NC, USA). Images were captured using a Canon powershot SX500 IS digital camera (Canon, Inc., Tokyo, Japan).
Statistical analysis. Results are expressed as the mean \pm standard error for five independent rats per group. The statistical significance of the differences between groups was assessed using analysis of variance and post hoc descriptive analysis with SPSS software for Windows, version 11.5 (SPSS, Inc., Chicago, IL, USA). $\mathrm{P}<0.05$ was considered to indicate a statistically significant difference.

\section{Results}

Changes in the serum levels of insulin, glucose and various lipid parameters. As shown in Table II, the induction of T2DM and IR increased the serum levels of glucose, TC, TG, LDL and VLDL, while decreasing the levels of HDL and insulin. By contrast, metformin administration for 4 weeks mitigated these elevations in all the parameters measured and increased the HDL levels and insulin secretion, supporting the beneficial effects of metformin in the treatment of IR and T2DM.

Metformin normalizes the T2DM-induced alterations in the expression levels of genes associated with lipid metabolism. Semi-quantitative RT-PCR analysis was performed for hepatic acyl-CoA oxidase (ACO), carnitine palmitoyl transferase-1 (CPT-1), apolipoprotein C-III (apo C-III) and fetuin-A in the normal control, T2DM and T2DM + metformin rats. During T2DM and IR, a disturbance in lipid profiles typically occurs and alterations in the expression of genes associated with lipid metabolism may be observed (6). Therefore, alterations in the expression levels of ACO, CPT-1, apo C-III and fetuin-A were analyzed in the rat livers. Fatty acid oxidation was reduced during IR, as indicated by the expression levels of ACO and CPT-1 (Fig. 1A and B). However, metformin 
Table II. Serum changes in insulin, glucose and lipid profiles during insulin resistance and following metformin administration.

\begin{tabular}{lcrr}
\hline Parameter & Control & Type 2 diabetes & Metformin \\
\hline Insulin (IU/l) & $4.5 \pm 0.5$ & $3.4 \pm 2.5^{\mathrm{a}}$ & $5.6 \pm 1.4^{\mathrm{b}}$ \\
Glucose (mg/dl) & $85.2 \pm 10.6$ & $165.5 \pm 15.6^{\mathrm{a}}$ & $75.5 \pm 9.4^{\mathrm{b}}$ \\
Trigylcerides (mg/dl) & $98.3 \pm 6.0$ & $195.7 \pm 10.5^{\mathrm{a}}$ & $80.6 \pm 5.2^{\mathrm{b}}$ \\
Cholesterol (mg/dl) & $118.6 \pm 2.9$ & $190.6 \pm 4.4^{\mathrm{a}}$ & $103.6 \pm 3.5^{\mathrm{b}}$ \\
LDL (mg/dl) & $57.6 \pm 4.4$ & $208.6 \pm 9.6^{\mathrm{a}}$ & $58.6 \pm 1.8^{\mathrm{b}}$ \\
VLDL (mg/dl) & $19.6 \pm 2.1$ & $38.0 \pm 2.1^{\mathrm{a}}$ & $17.3 \pm 1.8^{\mathrm{b}}$ \\
HDL $(\mathrm{mg} / \mathrm{dl})$ & $34.0 \pm 1.0$ & $23.6 \pm 2.1^{\mathrm{a}}$ & $32.6 \pm 1.2^{\mathrm{b}}$ \\
\end{tabular}

Values are expressed as the mean \pm standard error for three independent experiments per treatment. ${ }^{a} \mathrm{P}<0.05$, vs. control; ${ }^{\text {b }}<<0.05$, vs. insulin resistance group. LDL, low-density lipoprotein; VLDL, very low-density lipoprotein ; HDL, high-density lipoprotein.
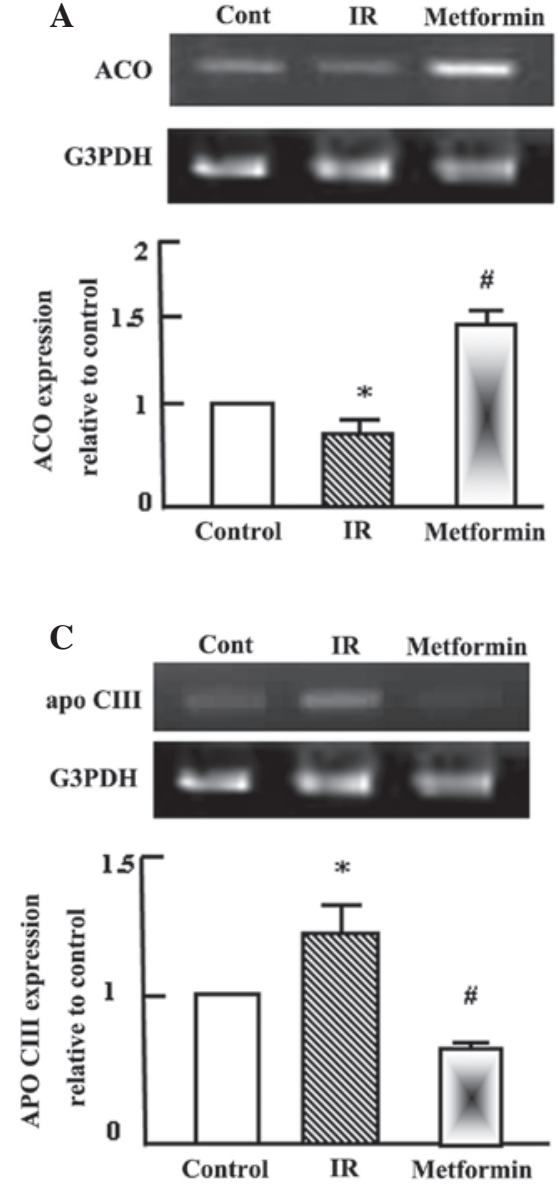
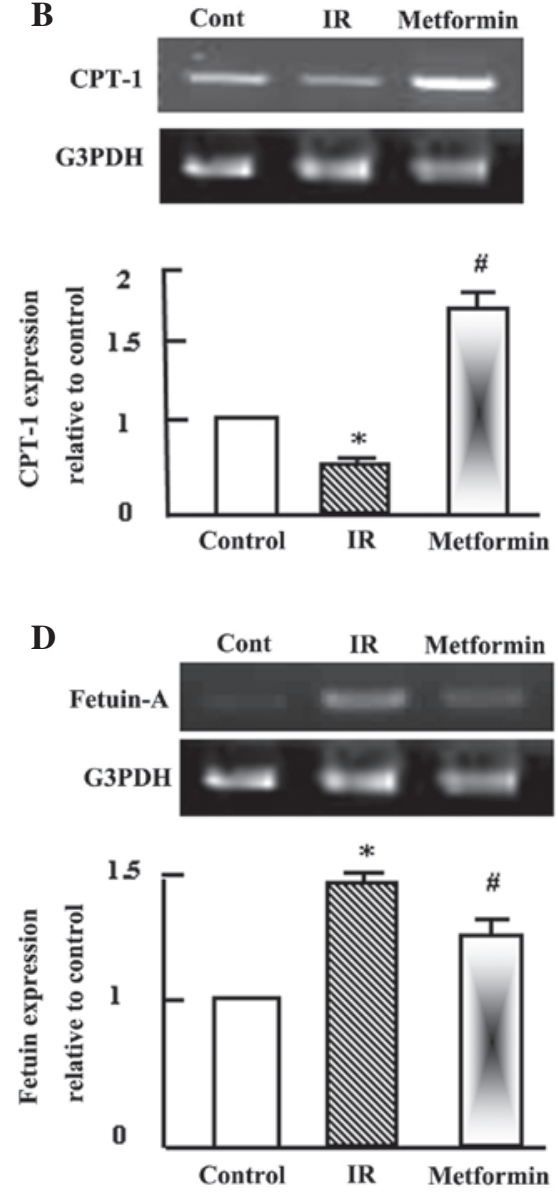

Figure 1. Semi-quantitative reverse transcription-polymerase chain reaction (RT-PCR) analysis of (A) ACO, (B) CPT-1, (C) apo C-III and (D) fetuin-A expression in the liver tissue of the control, IR and metformin-administered rats. RNA (1 mg) was extracted, reverse transcribed and RT-PCR analysis was conducted to assess ACO, CPT-1, apo C-III and fetuin-A expression, as described in the materials and methods. Densitometric analysis was conducted for three independent experiments, and data are presented as the mean \pm standard error for the three independent experiments. ${ }^{*} \mathrm{P}<0.05$, vs. control; ${ }^{\sharp} \mathrm{P}<0.05$, vs. IR group. ACO, acyl-CoA oxidase; IR, insulin resistance; CPT-1, carnitine palmitoyl transferase-1; Apo C-III, apolipoprotein C-III; G3PDH, glyceraldehyde-3-phosphate dehydrogenase.

administration for 4 weeks increased the expression levels of ACO and CPT-1 (Fig. 1A and B), which appeared to improve the dyslipidemia observed in the T2DM rats. In contrast to ACO and CPT-1, the expression levels of apo C-III and fetuin-A increased in the T2DM rats, and metformin administration decreased their expression to approximately normal levels (Fig. 1C and D).
Metformin normalizes the T2DM-induced alterations in the expression levels of insulin signaling molecules. Semi-quantitative RT-PCR analysis was performed for hepatic insulin receptor substrate (IRS)-1 and IRS-2, fatty acid synthetase (FAS) and peroxisome proliferator activated receptor (PPAR)- $\alpha$ in the normal control, T2DM and $\mathrm{T} 2 \mathrm{DM}+$ metformin rats. As shown in Fig. 2A and B, 

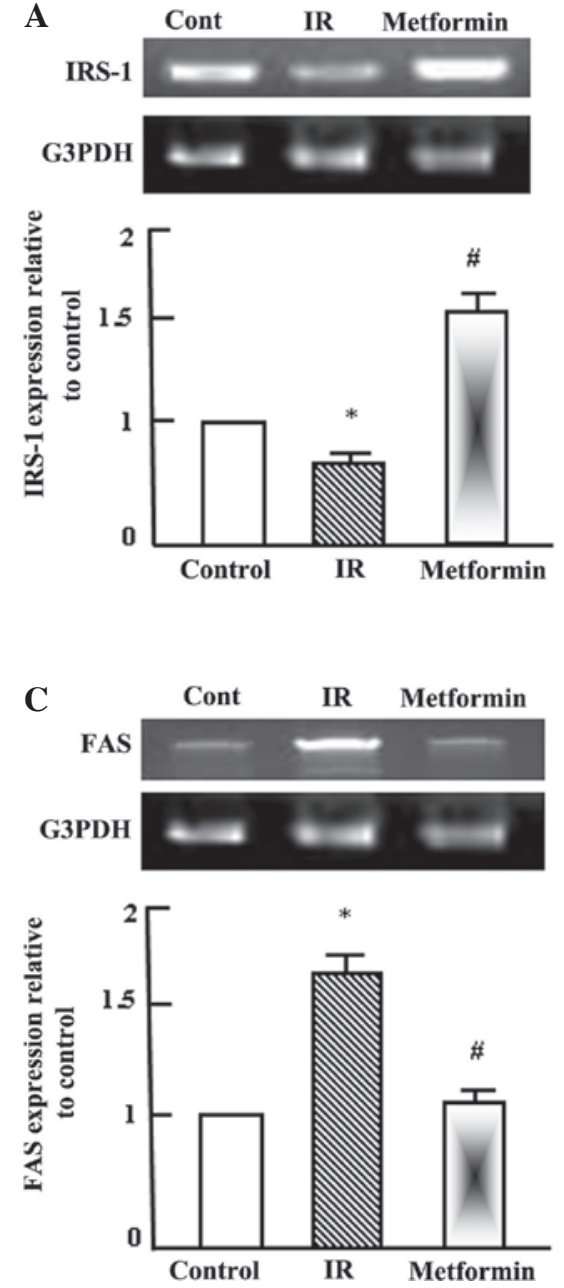
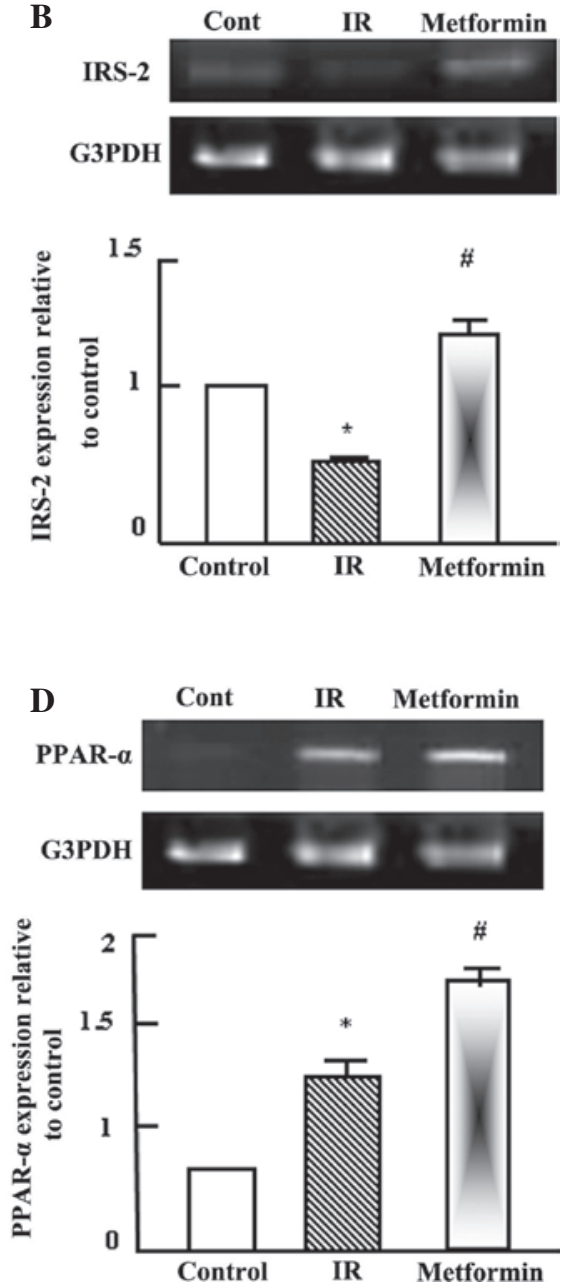

Figure 2. Semi-quantitative reverse transcription-polymerase chain reaction (RT-PCR) analysis of (A) IRS-1, (B) IRS-2, (C) FAS and (D) PPAR- $\alpha$ expression in the liver tissue of the control, IR and metformin-administered rats. RNA (1 mg) was extracted, reverse transcribed and RT-PCR analysis was conducted to assess IRS-1, IRS-2, FAS and PPAR- $\alpha$ expression, as described in the materials and methods. Densitometric analysis was conducted for three independent experiments, and data are presented as the mean \pm standard error for the three independent experiments. ${ }^{*} \mathrm{P}<0.05$, vs. control; ${ }^{*} \mathrm{P}<0.05$, vs. IR group. IR, insulin resistance; IRS, insulin receptor substrate; FAS, fatty acid synthetase; PPAR-, peroxisome proliferator activated receptor; G3PDH, glyceraldehyde-3-phosphate dehydrogenase.

insulin signaling was reduced as a result of IR and T2DM, as indicated by the reduction in the expression levels of IRS-1 and IRS-2. By contrast, the expression of FAS was increased during IR due to the increase in fatty acids synthesis and lipogenesis, while metformin administration normalized the FAS expression levels (Fig. 2C). PPAR- $\alpha$ expression was increased following the administration of metformin (Fig. 2D), which indicated that the effects of metformin were gene specific.

Metformin normalizes the expression levels of perilipin and retinol binding protein-4 (RBP-4) in adipose tissue. Semi-quantitative RT-PCR analysis was performed for perilipin and RBP-4 in the adipose tissue of the normal control, $\mathrm{T} 2 \mathrm{DM}$ and $\mathrm{T} 2 \mathrm{DM}+$ metformin rats. As shown in Fig. 3, perilipin expression levels decreased significantly following the induction of T2DM and IR, while RBP-4 expression levels increased. Administration of metformin to the T2DM rats normalized the perilipin expression levels, as compared with the normal control and T2DM rats, and reduced RBP-4 expression after 4 weeks of administration.
Hepatic histopathological and pancreatic immunohistochemical changes in normal, T2DM and T2DM + metformin rats. Liver tissue from the healthy control rats exhibited a normal hepatic architecture, represented by normal hepatic lobules with a thin walled central vein and hepatic cords radiating towards the periphery, alternating with hepatic sinusoids (Fig. 4A). The liver tissue of the T2DM/IR rats presented with signet-ring hepatocyte morphology due to the extensive accumulation of fat replacing the hepatic cytoplasm or appearing as numerous small fat droplets (Fig. 4B). However, the liver tissue collected from the T2DM + metformin rats exhibited restoration of the normal hepatic architecture, with a reduction in the degree of fat droplet accumulation from the hepatocyte cytoplasm and regeneration of the hepatic parenchyma (Fig. 1C). The pancreas of the healthy control rats presented a normal architecture with normal insulin expression in the pancreatic $\beta$ cells (Fig. 4D). However, the pancreatic tissue samples from the T2DM rats exhibited a reduction in the expression of insulin, with mild atrophy of the pancreatic $\beta$ cells (Fig. 4E). Finally, the pancreas of the $\mathrm{T} 2 \mathrm{DM}+$ metformin rats exhibited regenerative restora- 

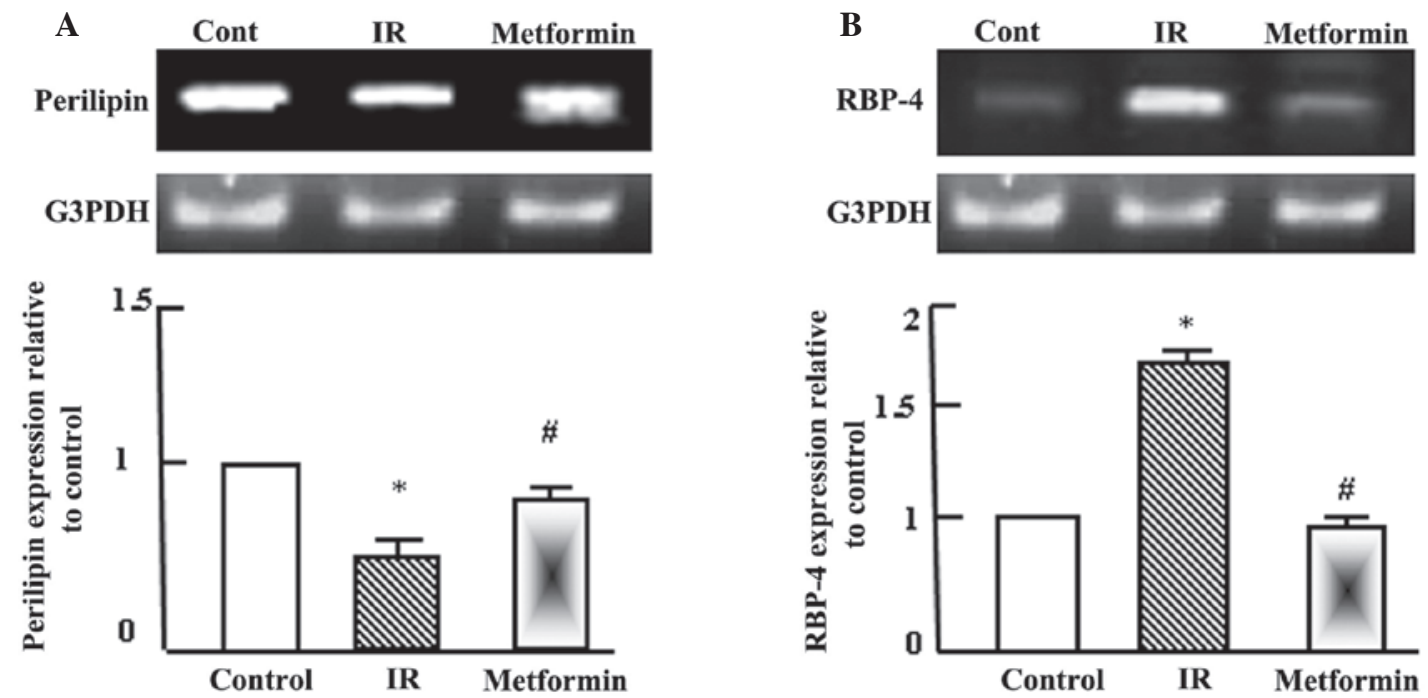

Figure 3. Semi-quantitative reverse transcription-polymerase chain reaction (RT-PCR) analysis of (A) perilipin and (B) RBP-4 expression in adipose tissue of the control, IR and metformin-administered rats. RNA was extracted, reverse transcribed (1 mg) and RT-PCR analysis was conducted to assess perilipin and RBP-4 expression, as described in the materials and methods. Densitometric analysis was conducted for three independent experiments, and data are presented as the mean \pm standard error for the three independent experiments. ${ }^{*} \mathrm{P}<0.05$, vs. control; ${ }^{\#} \mathrm{P}<0.05$, vs. IR group. IR, insulin resistance; RBP-4, retinol binding protein-4; G3PDH, glyceraldehyde-3-phosphate dehydrogenase.

A

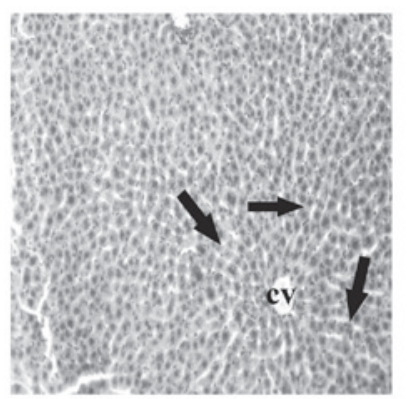

D

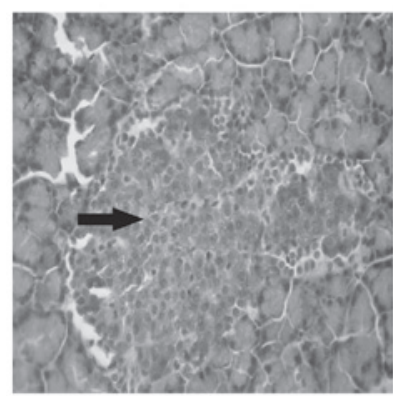

B

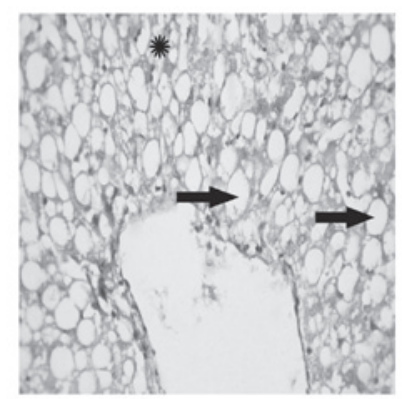

$\mathbf{E}$

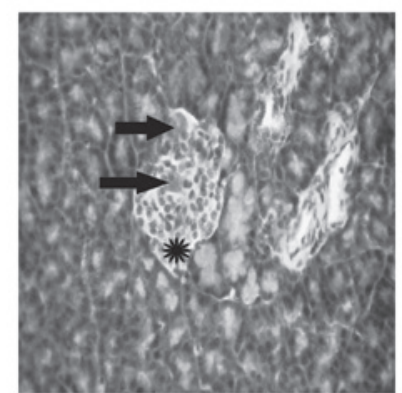

C

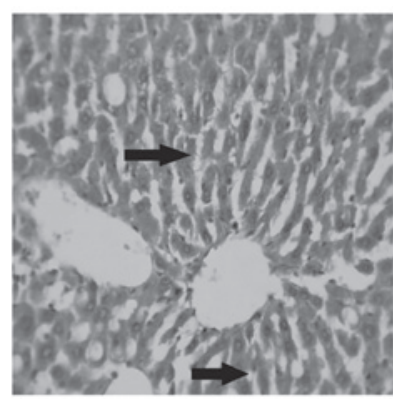

$\mathbf{F}$

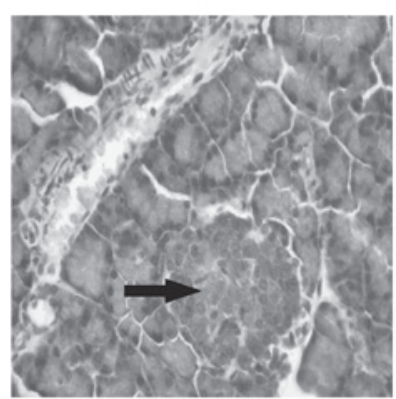

Figure 4. Photomicrographs of various tissue samples stained with hematoxylin and eosin. (A) Liver tissue from a healthy control rat showing a normal hepatic architecture, represented as hepatic lobules with a thin walled central vein and hepatic cords (arrows) radiating towards the periphery that alternate with hepatic sinusoids (magnification, x300). (B) Liver tissue from a rat with insulin resistance (IR) showing a signet-ring appearance of hepatocytes due to the accumulation of fat extensively replacing the hepatic cytoplasm (arrow), or appearing as multiple small fat droplets (indicated by *; magnification, x300). (C) Liver tissue from an IR rat administered metformin showing the restoration of a normal hepatic architecture with reduced fat droplets from the hepatocyte cytoplasm (arrows) and the regeneration of hepatic parenchyma (magnification, x150). (D) Pancreatic tissue of a healthy control rat showing a normal architecture with normal expression of insulin in the $\beta$ cells (arrow; magnification, $x 300$ ). (E) Pancreatic tissue of an IR rat showing a reduction in the expression of insulin in the $\beta$ cells (arrows), with mild atrophy of the $\beta$ cells (indicated by *;magnification, x300). (F) Pancreatic tissue of an IR rat administered metformin showing the restoration of normal expression of insulin in the pancreatic $\beta$ cells (arrow; magnification, $\times 300$ ).

tion of normal expression of insulin in the pancreatic $\beta$ cells (Fig. 4F).

\section{Discussion}

In the present study, metformin was observed to ameliorate a number of the alterations in the serum and gene expres- sion levels that occurred as a result of T2DM/IR. Metformin ameliorated the alterations associated with IR, including lipid profiles, insulin expression and glucose levels. Furthermore, the T2DM-induced alterations in the expression levels of genes associated with lipid metabolism were normalized following metformin administration. The metabolic action of insulin in liver tissue occurs in response to the activation of 
the phosphatidyl inositol 3 kinase (PI3K) pathway, in which the insulin receptor is activated by autophosphorylation after binding to insulin (21). The activated insulin receptor subsequently phosphorylates selective tyrosine residues on IRS and induces the binding of IRS-1 and IRS-2 to PI3K, phosphorylating serine and activating protein kinase $\mathrm{B}(\mathrm{PKB})$. The activation of $\mathrm{PKB}$ is crucial for various processes, including glucose transport in the liver, muscle and adipose tissue, glycogen synthesis in the liver and muscle tissue and lipogenesis in the adipose tissue (22). The phosphorylation of IRS-1 by serine kinases disrupts the interaction between the insulin receptor and IRS, thus preventing the tyrosine phosphorylation of IRS (21). These previously observed mechanisms are consistent with the results of the present study, since IR was observed to downregulate insulin receptor signaling, while metformin upregulated insulin receptor signaling and mitigated the dyslipidemia associated with IR. In accordance, Elmadhun et al (22) demonstrated that metformin supplementation in a T2DM rat model significantly altered the insulin signaling pathway. The insulin signaling cascade is initiated by insulin binding to the insulin receptor, resulting in tyrosine phosphorylation of IRS, which activates IRS and allows binding to PI3K. Subsequently, PI3K activates PKB, which initiates the translocation of intracellular glucose transporter-4 (GLUT-4) vesicles to the plasma membrane (23).

The administration of metformin has been previously demonstrated to improve hepatic insulin sensitivity by modulating the insulin signaling pathway in high fat-fructose diet (HFFD)-fed IR rats (24). Consumption of a HFFD resulted in hyperglycemia, hyperinsulinemia, increased gluconeogenesis and the reduced tyrosine phosphorylation of insulin receptor- $\beta$ and IRS-1 (24). The authors observed that the administration of metformin reversed all the parameters altered by consumption of the HFFD. The present study demonstrated that the improved insulin sensitivity induced as a result of metformin treatment is mediated by enhanced tyrosine phosphorylation of IRS-1 and IRS-2. Grisouard et al (25) and unpublished data from the current research group indicated that metformin increases the mRNA expression levels of GLUT-4, and subsequently increases GLUT-4 protein levels in storage vesicles and the plasma membrane. Notably, GLUT-4 levels are lower in the adipocytes of obese patients and individuals with diminished glucose tolerance or T2DM (26).

Numerous approaches have been investigated with the aim to mitigate the damaging effects of IR by reducing the accumulation of detrimental lipids in muscle and liver tissue. Certain approaches have attempted to decrease the availability of TG and non-esterified fatty acids in circulation, in which the administration of PPAR- $\alpha$ agonists has been demonstrated to be successful (27). PPAR- $\alpha$ is a transcription factor that exerts notable effects on lipid homeostasis by regulating the expression of genes involved in lipid metabolism (27). The transcription factor is primarily expressed in the liver, where it regulates the transcription of genes involved in lipid uptake and oxidation, such as acyl-CoA synthetase (ACS), ACO, CPT-1 and lipoprotein lipase (LPL) (28). The activation of these factors is hypothesized to result in the sequestration of lipid into the liver for oxidation, which is demonstrated by the results of the present study (Fig. 2D). This activity putatively reduces the quantity of lipid available to the skeletal muscle, which is the most prevalent insulin-sensitive tissue type in humans (28). Following activation, PPAR- $\alpha$ is able to heterodimerize with the retinoid $\mathrm{X}$ receptor and bind with peroxisome proliferator response elements, which are located in the promoter regions of various genes, such as LPL (29), ACO (30), ACS (31) and CPT-1 (32), the transcription of which is activated by the complex. However, the expression of apo C-III is suppressed by PPAR- $\alpha$ activation due to the competition for a response element between the PPAR- $\alpha$-retinoid $\mathrm{X}$ receptor heterodimer and hepatocyte nuclear factor-4, a liver enriched transcriptional activator (33).

The results of the present study indicate that metformin administration reduces the hepatic mRNA expression of apo C-III. Apo C-III inhibits the hydrolysing function of LPL, which is consistent with the observed reduction in the hepatic expression levels of apo $\mathrm{C}$-III in the $\mathrm{T} 2 \mathrm{DM}+$ metformin rats. The metformin-induced elevation in the mRNA expression levels of CPT-1 in the hepatic tissue may account for the increased level of $\beta$-oxidation in the liver tissue. Although metformin was not shown to directly enhance the expression of PPAR- $\alpha$, the drug was observed to increase the mRNA expression levels of hepatic ACO, which is a well-known marker of PPAR- $\alpha$ activation. In addition, similar to typical PPAR- $\alpha$ activators, metformin reduced the mass of visceral fat. These results indicate that metformin may function as a PPAR- $\alpha$ agonist.

In a previous study, significant reductions were observed in the plasma levels of TG, TC and insulin, body weight, abdominal fat weight, hepatic lipid content and hepatic FAS expression in laying hens with non-alcoholic fatty livers administered metformin at $100 \mathrm{mg} / \mathrm{kg}$ body weight; however, a significant increase was observed in the expression levels of CPT-1 (34). Collectively, these previous findings and the results of the present study confirm the efficacy of metformin for the treatment of IR. In addition to the induction of lipolytic enzymes, metformin may also function as an activator of adenosine monophosphate-activated protein kinase (AMPK) (35). The activation of AMPK phosphorylates acyl-CoA cyclase (ACC) and subsequently inhibits its activity, which leads to a reduction in malonyl-CoA synthesis. This reduction may in turn stimulate the transportation of fatty acids into the mitochondria for $\beta$-oxidation via the upregulation of CPT-1, a transporter of fatty acids (36). Furthermore, metformin increases the phosphorylation of mitogen-activated protein kinase (MAPK) and ACC, and the expression of CPT-1, which suggests that metformin enhances fatty acid $\beta$-oxidation.

In addition to enhancing the rate of lipolysis and fatty acid oxidation in mitochondria, metformin reduces the expression of FAS, a lipogenic protein. FAS catalyzes the final step in the fatty acid biosynthetic pathway and is crucial for determining the maximum capacity of a tissue for synthesizing fatty acids via the de novo pathway (37). The results of the present study indicate that metformin may exert this lipid-reducing activity via the concerted modulation of lipolysis and lipogenesis, in which the expression levels of hepatic genes associated with lipid metabolism are altered. These findings are consistent with those of a previous clinical study, which indicated that 
a combination of insulin and metformin reduced hepatic steatosis and TG levels in patients with T2DM (38). In addition, Bhalla et al (39) observed that metformin reduced the mRNA and protein expression levels of a number of lipogenic enzymes, such as FAS, which is consistent with the results of the present study.

Fetuin-A is a $60 \mathrm{kDa}$ glycoprotein that is secreted by hepatocytes, and can be used as a biomarker of liver function and inflammation. Fetuin-A modulates insulin signal transduction by inhibiting the insulin receptor tyrosine kinase in the liver and skeletal tissue, as well as inhibiting the autophosphorylation of the insulin receptor in vitro and in vivo, which ultimately results in IR (10). Furthermore, increased fetuin-A levels have been associated with obesity, IR, metabolic syndrome, liver fat accumulation and an increased risk of T2DM (10). In the present study, fetuin-A expression was shown to increase in the T2DM rats, while treatment with metformin was able to restore fetuin-A expression. Fetuin-A has been demonstrated to suppress the generation of adiponectin in adipose tissue, and fetuin-A treatment in wild-type mice may result in hypoadiponectinemia (10). In addition, reduced levels of adiponectin may induce the accumulation of fat in the liver, resulting in increased fetuin-A secretion (40). Therefore, elevated fetuin-A expression may lead to reduced levels of adiponectin in obese patients with T2DM, as indicated in a study by Mori et al (10).

An additional lipid metabolism regulating gene is perilipin, which has the function of coating the surface of intracellular lipid droplets in adipocytes. Perilipin modulates lipolysis (41) through limiting the interaction between lipase and the TG core stored within the lipid droplets (42). The results of the present study demonstrated that metformin normalized the IR-induced reduction in the expression of perilipin in the adipose tissue of T2DM rats. In addition, the treatment of adipocytes with metformin has been shown to attenuate lipolytic activity, stimulated by tumor necrosis factor (TNF)- $\alpha$, isoproterenol or a high dose of glucose (43). The inhibitory effect of metformin on TNF- $\alpha$-stimulated lipolysis is accompanied by the suppressed phosphorylation of extracellular signal-regulated kinases $1 / 2$ and the reversed downregulation of perilipin. These two effects may primarily account for the molecular basis underlying the antilipolytic function of metformin in TNF- $\alpha$-stimulated adipocytes.

A previous study revealed that RBP-4 is the only specific transport protein for retinol (vitamin A) that is able to deliver retinol to tissues from the blood (44). RBP-4 is highly expressed in adipose tissue, as compared with liver tissue, and is strongly associated with endothelial function (44). Fischer et al (45) reported that a reduction in RBP-4 secretion results in improved insulin levels (44). Previously, RBP-4 serum levels appeared to be associated with insulin sensitivity, and were increased in obese non-diabetic subjects (44) and patients with T2DM (46). Limited data is available with regard to the exact role of RBP-4 in human metabolism. However, a previous study reported a marked correlation between RBP-4 and IR in non-diabetic subjects without a medical or family history of diabetes (47).

Furthermore, a prior study demonstrated that high secretion of RBP-4 by adipocytes reduced the expression of GLUT-4 in adipose tissue, which is commonly observed in patients with T2DM (47). The results of the present study are consistent with those of Tajtáková et al (48), since obese patients with T2DM treated with metformin were shown to exhibit lower plasma RBP-4 levels compared with obese patients, indicating that metformin may improve total insulin sensitivity through RBP-4. Recently, the insulin sensitizer, rosiglitazone, has been reported to significantly decrease the RBP-4 levels, and thus, mitigate IR (49). Therefore, RBP-4 may be useful as a clinical marker for identifying individuals at risk of developing IR or T2DM. In addition, it is possible that metformin exerts its effects via the regulation of RBP-4.

$\mathrm{T} 2 \mathrm{DM}$ is characterized by progressive $\beta$ cell destruction, as a result of chronic IR and the loss of $\beta$ cell mass and function, as shown in Fig. 4E and demonstrated by previous studies $(50,51)$. The primary mechanism underlying the reduction in $\beta$ cell mass in patients with T2DM is the apoptosis of $\beta$ cells in all diabetic patients. However, $\beta$ cell mass is affected by numerous factors, including cell size, rate of cell renewal or neogenesis and the rate of apoptosis (51). In patients with T2DM, pancreatic $\beta$ cells are unable to secrete sufficient quantities of insulin to compensate for the reduced insulin sensitivity, which is primarily a result of insulin secretion dysfunction and a marked reduction in the number of functional $\beta$ cells (Fig. 4E) (50-54). Consistent with these findings, the present study observed similar effects, as metformin administration participated in the regeneration of the capacity of pancreatic $\beta$ cells to secrete insulin. In the $\mathrm{T} 2 \mathrm{DM}+$ metformin group rats, restoration of normal $\beta$ cell mass was observed. Thus, the antidiabetic effects of metformin may occur as a result of the reduction of hepatic gluconeogenesis, the regeneration of hepatocytes (Fig. 4C), reduced glucose absorption and increased insulin sensitivity (Fig. 4F), through the increase in glucose uptake and utilization $(55,56)$.

In conclusion, the results of the present study demonstrated the beneficial effects of metformin in the treatment of IR. Metformin was observed to normalize IR-associated dyslipidemia. Furthermore, metformin was demonstrated to regulate the expression of various genes associated with lipid metabolism. Notably, close associations were observed between metformin and a number of genes expressed in the liver and adipose tissue, including fetuin-A, perilipin and RBP-4. However, further studies are required to outline the molecular signaling pathways affected by metformin in the amelioration of IR.

\section{Acknowledgements}

The study was supported by a grant from The Deans of Scientific Affairs, Taif University (no. 2220-1-1434; Ta'if, Saudi Arabia).

\section{References}

1. Shaw JE, Sicree RA and Zimmet PZ: Global estimates of the prevalence of diabetes for 2010 and 2030. Diabetes Res Clin Pract 87: 4-14, 2010.

2. Roglic G and Unwin N: Mortality attributable to diabetes: Estimates for the year 2010. Diabetes Res Clin Pract 87: 15-19, 2010.

3. Stumvoll M, Goldstein BJ and van Haeften TW: Type 2 diabetes: Principles of pathogenesis and therapy. Lancet 365: 1333-1346, 2005.

4. Rewers M, Zaccaro D, D'Agostino R, Haffner S, Saad MF, Selby JV, Bergman R and Savage P; Insulin Resistance Atherosclerosis Study Investigators: Insulin sensitivity, insulinemia and coronary artery disease: the Insulin Resistance Atherosclerosis study. Diabetes Care 27: 781-787, 2004. 
5. Myers MG Jr and Olson DP: Central nervous system control of metabolism. Nature 491: 357-363, 2012

6. Reaven GM: The insulin resistance syndrome: Definition and dietary approaches to treatment. Annu Rev Nutr 25: 391-406, 2005.

7. Bouche C, Lopez X, Fleischman A, Cypess AM, O'Shea S, Stefanovski D, Bergman RN, Rogatsky E, Stein DT, Kahn CR, et al: Insulin enhances glucose-stimulated insulin secretion in healthy humans. Proc Natl Acad Sci USA 107: 4770-4775, 2010.

8. Rhodes CJ, White MF, Leahy JL and Kahn SE: Direct autocrine action of insulin on $\beta$-cells: Does it make physiological sense? Diabetes 62: 2157-2163, 2013.

9. Jung TW, Youn BS, Choi HY, Lee SY, Hong HC, Yang SJ, Yoo HJ, Kim BH, Baik SH and Choi KM: Salsalate and adiponectin ameliorate hepatic steatosis by inhibition of the hepatokine fetuin-A. Biochem Pharmacol 86: 960-969, 2013.

10. Mori K, Emoto M and Inaba M: Fetuin-A: a multifunctional protein. Recent Pat Endocr Metab Immune Drug Discov 5: 124-146, 2011.

11. Syed Ikmal SI, Zaman Huri H, Vethakkan SR and Wan Ahmad WA: Potential biomarkers of insulin resistance and atherosclerosis in type 2 diabetes mellitus patients with coronary artery disease. Int J Endocrinol 2013: 698567, 2013.

12. Sztalryd C and Kimmel AR: Perilipins: lipid droplet coat proteins adapted for tissue-specific energy storage and utilization and lipid cytoprotection. Biochimie 96: 96-101, 2014.

13. Zhou G, Myers R, Li Y, Chen Y, et al: Role of AMP-activated protein kinase in mechanism of metformin action. J Clin Invest 108: 1167-1174, 2001.

14. Woods YL, Petrie JR and Sutherland C: Dissecting insulin signaling pathways: Individualised therapeutic targets for diagnosis and treatment of insulin resistant states. Endocr Metab Immune Disord Drug Targets 9: 187-198, 2009.

15. Radziuk J, Zhang Z, Wiernsperger N and Pye S: Effects of metformin on lactate uptake and gluconeogenesis in the perfused rat liver. Diabetes 46: 1406-1413, 1997.

16. Nathan DM, Buse JB, Davidson MB, Ferrannini E, Holman RR, Sherwin R and Zinman B; American Diabetes Association, European Association for Study of Diabetes: Medical management of hyperglycemia in type 2 diabetes: A consensus algorithm for the initiation and adjustment of therapy: A consensus statement of the American Diabetes Association and the European Association for the Study of Diabetes. Diabetes Care 32: 193-203, 2009.

17. Diamanti-Kandarakis E, Christakou CD, Kandaraki E and Economou FN: Metformin: an old medication of new fashion: evolving new molecular mechanisms and clinical implications in polycystic ovary syndrome. Eur J Endocrinol 162: 193-212, 2010.

18. Hundal RS and Inzucchi SE: Metformin: new understandings, new uses. Drugs 63: 1879-1894, 2003.

19. Srinivasan K, Viswanad B, Asrat L, Kaul CL and Ramarao P: Combination of high-fat diet-fed and low-dose streptozotocin-treated rat: A model for type 2 diabetes and pharmacological screening. Pharmacol Res 52: 313-320, 2005.

20. Bancroft JD and Gamble M: Theory and Practice of Histological Techniques. 6th edition. Churchill Livingstone Elsevier, Philadelphia, PA, pp126-127, 2008.

21. Werner ED, Lee J, Hansen L, Yuan M and Shoelson SE: Insulin resistance due to phosphorylation of insulin receptor substrate-1 at serine 302. J Biol Chem 279: 35298-35305, 2004

22. Elmadhun NY, Lassaletta AD, Chu LM and Sellke FW: Metformin alters the insulin signaling pathway in ischemic cardiac tissue in a swine model of metabolic syndrome. J Thorac Cardiovasc Surg 145: 258-266, 2013

23. Sykiotis GP and Papavassiliou AG: Serine phosphorylation of insulin receptor substrate-1: A novel target for the reversal of insulin resistance. Mol Endocrinol 15: 1864-1869, 2001.

24. Yogalakshmi B, Bhuvaneswari S, Sreeja S and Anuradha CV: Grape seed proanthocyanidins and metformin act by different mechanisms to promote insulin signaling in rats fed high calorie diet. J Cell Commun Signal 8: 13-22, 2014.

25. Grisouard J, Timper K, Radimerski TM, Frey DM, Peterli R, Kola B, Korbonits M, Herrmann P, Krähenbühl S, Zulewski $\mathrm{H}$, et al: Mechanisms of metformin action on glucose transport and metabolism in human adipocytes. Biochem Pharmacol 80: 1736-1745, 2010.

26. Shepherd PR and Kahn BB: Glucose transporters and insulin action - implications for insulin resistance and diabetes mellitus. N Engl J Med 341: 248-257, 1999.
27. Ye JM, Doyle PJ, Iglesias MA, Watson DG, Cooney GJ and Kraegen EW: Peroxisome proliferator-activated receptor (PPAR)- $\alpha$ activation lowers muscle lipids and improves insulin sensitivity in high fat-fed rats: Comparison with PPAR- $\gamma$ activation. Diabetes 50: 411-417, 2001

28. Escher P and Wahli W: Peroxisome proliferator-activated receptors: Insight into multiple cellular functions. Mutat Res 448: 121-138, 2000.

29. Schoonjans K, Peinado-Onsurbe J, Lefebvre AM, Heyman RA, Briggs M, Deeb S, Staels B and Auwerx J: PPAR $\alpha$ and PPAR activators direct a distinct tissue-specific transcriptional response via a PPRE in the lipoprotein lipase gene. EMBO J 15: 5336-5348, 1996

30. Kliewer SA, Umesono K, Noonan DJ, Heyman RA and Evans RM: Convergence of 9-cis retinoic acid and peroxisome proliferator signalling pathways through heterodimer formation of their receptors. Nature 358: 771-774, 1992.

31. Schoonjans K, Watanabe M, Suzuki H, Mahfoudi A, Krey G, Wahli W, Grimaldi P, Staels B, Yamamoto T and Auwerx J: Induction of the acyl-coenzyme A synthetase gene by fibrates and fatty acids is mediated by a peroxisome proliferator response element in the C promoter. J Biol Chem 270: 19269-19276, 1995.

32. Louet JF, Chatelain F, Decaux JF, Park EA, Kohl C, Pineau T, Girard J and Pegorier JP: Long-chain fatty acids regulate liver carnitine palmitoyltransferase 1 gene (L-CPT I) expression through a peroxisome proliferator-activated receptor $\alpha$ (PPAR $\alpha$ )-independent pathway. Biochem J 354: 189-197, 2001.

33. Hertz R, Bishara-Shieban J and Bar-Tana J: Mode of action of peroxisome proliferators as hypolipidemic drugs. Suppression of apolipoprotein C-III. J Biol Chem 270: 13470-13475, 1995.

34. Chen WL, Wei HW, Chiu WZ, Kang CH, Lin TH, Hung CC, Chen MC, Shieh MS, Lee CC and Lee HM: Metformin regulates hepatic lipid metabolism through activating AMP-activated protein kinase and inducing ATGL in laying hens. Eur J Pharmacol 671: 107-112, 2011.

35. Musi N, Hirshman MF, Nygren J, Svanfeldt M, Bavenholm P, Rooyackers O, Zhou G, Williamson JM, Ljunqvist O, Efendic S, et al: Metformin increases AMP-activated protein kinase activity in skeletal muscle of subjects with type 2 diabetes. Diabetes 51: 2074-2081, 2002.

36. Schreurs M, Kuipers F and van der Leij FR: Regulatory enzymes of mitochondrial beta-oxidation as targets for treatment of the metabolic syndrome. Obes Rev 11: 380-388, 2010.

37. Clarke SD and Jump DB: Regulation of gene transcription by polyunsaturated fatty acids. Prog Lipid Res 32: 139-149, 1993.

38. Lingvay I, Raskin P and Szczepaniak LS: Effect of insulin-metformin combination on hepatic steatosis in patients with type 2 diabetes. J Diabetes Complications 21: 137-142, 2007.

39. Bhalla K, Hwang BJ, Dewi RE, Twaddel W, Goloubeva OG, Wong KK, Saxena NK, Biswal S and Girnun GD: Metformin prevents liver tumorigenesis by inhibiting pathways driving hepatic lipogenesis. Cancer Prev Res (Phila) 5: 544-552, 2012.

40. Roden M: Mechanisms of disease: Hepatic steatosis in type 2 diabetes - pathogenesis and clinical relevance. Nat Clin Pract Endocrinol Metab 2: 335-348, 2006.

41. He J, Jiang H, Tansey JT, Tang C, Pu S and Xu G: Calyculin and okadaic acid promote perilipin phosphorylation and increase lipolysis in primary rat adipocytes. Biochim Biophys Acta 1761: 247-255, 2006

42. Sztalryd C, Xu G, Dorward H, Tansey JT, Contreras JA, Kimmel AR and Londos C: Perilipin A is essential for the translocation of hormone-sensitive lipase during lipolytic activation. J Cell Biol 161: 1093-1103, 2003.

43. Ren T, He J, Jiang H, Zu L, Pu S, Guo X and Xu G: Metformin reduces lipolysis in primary rat adipocytes stimulated by tumor necrosis factor- $\alpha$ or isoproterenol. J Mol Endocrinol 37: 175-183, 2006.

44. Yang Q, Graham TE, Mody N, Preitner F, Peroni OD, Zabolotny JM, Kotani K, Quadro L and Kahn BB: Serum retinol binding protein 4 contributes to insulin resistance in obesity and type 2 diabetes. Nature 436: 356-362, 2005.

45. Fischer CP, Perstrup LB, Berntsen A, Eskildsen $P$ and Pedersen BK: Elevated plasma interleukin-18 is a marker of insulin-resistance in type 2 diabetic and non-diabetic humans. Clin Immunol 117: 152-160, 2005

46. Cho YM, Youn BS, Lee H, Lee N, Min SS, Kwak SH, Lee HK and Park KS: Plasma retinol-binding protein-4 concentrations are elevated in human subjects with impaired glucose tolerance and type 2 diabetes. Diabetes Care 29: 2457-2461, 2006. 
47. Gavi S, Stuart LM, Kelly P, Melendez MM, Mynarcik DC, Gelato MC and McNurlan MA: Retinol-binding protein 4 is associated with insulin resistance and body fat distribution in nonobese subjects without type 2 diabetes. J Clin Endocrinol Metab 92: 1886-1890, 2007.

48. Tajtáková M, Semanová Z, Ivancová G, Petrovicová J, Donicová V and Zemberová E: Serum level of retinol-binding protein 4 in obese patients with insulin resistance and in patients with type 2 diabetes treated with metformin. Vnitr Lek 53: 960-963, 2007 (In Slovak).

49. Fang P, Shi M, Yu M, Guo L, Bo P and Zhang Z: Endogenous peptides as risk markers to assess the development of insulin resistance. Peptides 51: 9-14, 2014.

50. Stoffers DA: The development of beta-cell mass: Recent progress and potential role of GLP-1. Horm Metab Res 36: 811-821, 2004

51. Butler AE, Janson J, Bonner-Weir S, Ritzel R, Rizza RA and Butler PC: Beta-cell deficit and increased beta-cell apoptosis in humans with type 2 diabetes. Diabetes 52: 102-110, 2003.
52. Cozar-Castellano I, Fiaschi-Taesch N, Bigatel TA, Takane KK, Garcia-Ocaña A, Vasavada R and Stewart AF: Molecular control of cell cycle progression in the pancreatic beta-cell. Endocr Rev 27: 356-370, 2006.

53. Kahn SE, Hull RL and Utzschneider KM: Mechanisms linking obesity to insulin resistance and type 2 diabetes. Nature 444: 840-846, 2006.

54. Marchetti P, Del Guerra S, Marselli L, Lupi R, Masini M, Pollera M, Bugliani M, Boggi U, Vistoli F, Mosca F and Del Prato S: Pancreatic islets from type 2 diabetic patients have functional defects and increased apoptosis that are ameliorated by metformin. J Clin Endocrinol Metab 89: 5535-5541, 2004.

55. Kral JG, Thung SN, Biron S, Hould FS, Lebel S, Marceau S, Simard S and Marceau P: Effects of surgical treatment of the metabolic syndrome on liver fibrosis and cirrhosis. Surgery 135: 48-58, 2004.

56. Kirpichnikov D, McFarlane SI and Sowers JR: Metformin: An update. Ann Intern Med 137: 25-33, 2002. 